\section{Fehler, grober}

G. Schumann

Hannover, Deutschland

\section{Englischer Begriff gross error}

Definition Messabweichung, die bei korrektem Arbeiten zu vermeiden wäre.

Beschreibung Grobe Fehler ( $\triangleright$ Fehler, grober) sind von systematischen Fehlern ( $\triangleright$ Messabweichung, systematische) zu unterscheiden. Als grobe Fehler werden beispielsweise die Nichteinhaltung der Standardarbeitsanweisungen, Verwechslungen von Reagenzien, Proben, Filtern oder Pipetten bezeichnet. Während die Ursachen solcher grober Fehler meist sofort erkennbar sind, können sie bei systematischen Fehlern nicht immer aufgedeckt werden. Die Differenzierung in systematische und grobe Fehler erfolgt gelegentlich subjektiv und dem Ausmaß der Abweichung entsprechend.

So kann die Verwendung einer unkorrekten Standardlösung zu einem groben Fehler führen, wenn versehentlich eine Stammlösung anstatt der Gebrauchsverdünnung eingesetzt wurde, und zu einem systematischen Fehler, wenn beim Ansetzen der Gebrauchsverdünnung eine nicht geeichte Pipette mit einer systematischen Minus-(bzw. Plus-)Abweichung benutzt wurde.

\section{Literatur}

Management in der Laboratoriumsmedizin (2000) Teil 1: Grundbegriffe. DIN 58936-1, 3.1.10.4. Beuth-Verlag, Berlin 